\title{
Medical Students' Knowledge About Children With Disabilities, Special Education Laws, and Social Services: A Preliminary Scale Development and Pilot Study
}

Nancy Vitalone-Raccaro, PhD; Mary Erin Sheppard, EdD; Jacqueline M. Kaari, DO

From the Casperson School of Graduate Studies at Drew University in Madison, New Jersey (Dr Vitalone-Raccaro); the Special Education Department at Saint Joseph's University in Philadelphia, Pennsylvania (Dr Sheppard); and the Cleveland Clinic in Twinsburg, Ohio (Dr Kaari). These data were presented as preliminary findings in poster format at the Society for Developmental and Behavioral Pediatrics 2015 Annual Meeting in Las Vegas, Nevada, and CEC Special Education Convention and Expo 2016 in St Louis, Missouri.

Financial Disclosures: None reported.

Support: None reported.

Address correspondence to Nancy Vitalone-Raccaro, PhD, Drew University, 36 Madison Ave, Madison, NJ 079401434.

Email: nvitaloneraccar@drew.
Context: In order to design undergraduate medical education responsive to the American Academy of Pediatrics' recommendation that physicians learn about special education law and practices, it is important to understand medical students' baseline knowledge about children with disabilities, special education law, available services, and the sources of this information.

Objectives: To develop an instrument to measure what second-year medical students know about children with disabilities, special education law, and available services; to determine the most common sources of this information; and to establish a baseline on which to design curricula that address this topic.

Methods: This study adopted a survey design. The survey took place in 1 school of osteopathic medicine in a Northeastern state of the United States. One hundred fifty medical students in their second year of full-time enrollment were invited to complete the survey. The instrument designed by the authors consisted of 30 items organized into a demographics section and 3 domains: (1) perceived level of knowledge about children with disabilities, (2) sources of information about children with disabilities, and (3) actual knowledge about children with disabilities and special education.

Results: Ninety-eight students (65\%) participated. Although students were accurate in self-assessment, their source of knowledge was limited. Medical students who identified personal experiences $(t=1.64)$ and coursework as their source of knowledge had more correct responses $(t=2.62)$.

Conclusion: This preliminary study demonstrated a lack of knowledge among second-year medical students with regard to children with disabilities, special education laws, and social services. Curricula emphasizing disabilities and special education along with longitudinal experiential training may be effective methods to deliver these topics.

J Am Osteopath Assoc. 2019;119(10):674-681

doi:10.7556/jaoa.2019.115

Keywords: Individuals With Disabilities Education Act, medical education, pediatrics, special education

he American Academy of Pediatrics endorses family-centered care, communitybased supports and services, and accessible, coordinated, and continuous support, ${ }^{1}$ with a focus on special education law and services ${ }^{2}$ as attributes of quality health care for children with disabilities. Physicians actualize these attributes by 
identifying children with developmental delays, facilitating referral to early intervention (EI) or special education services ${ }^{3}$ and promoting the well-being of all children in the educational setting and in health care. ${ }^{2}$

Children with disabilities are protected under 2 federal laws: The Individuals With Disabilities Education Act (IDEA) and Section 504 of the Rehabilitation Act of 1973. The IDEA ensures that people from birth to age 21 years with diagnosed disabilities are provided with a free appropriate public education in the least restrictive environment. ${ }^{4}$ Free appropriate public education mandates the provision of special education without cost to families in an appropriate school setting. The least restrictive environment mandate calls for children with disabilities to be educated with nondisabled peers to the maximum extent appropriate. A student is eligible for special education under IDEA if a disability has been diagnosed, the disability adversely affects educational performance, and specially designed instruction is required.

Early intervention for children from birth to 3 years of age is a component of IDEA that is intended to reduce potential adverse effects and enhance development. ${ }^{5}$ Children qualify for EI services if they have a developmental delay or a diagnosed condition that results in a high probability of developmental delay. ${ }^{6}$ Although states have discretion in setting eligibility criteria, IDEA guarantees supports and services for infants and toddlers and their families. ${ }^{7}$ In the event a person aged 3 to 21 years is not deemed eligible for special education services yet still needs accommodations to access the school curriculum, Section 504 of the Rehabilitation Act of 1973, a civil rights law designed to prohibit discrimination based on disability status, mandates provision of the necessary accommodations through a 504 Plan. $^{8}$

Physicians who understand special education laws and practices can help parents access services for their children, monitor school progress during well-visit appointments, increase collaboration with schools, and assist in the planning for the transition of older children with disabilities to adult services. Understanding special education, resource availability, and the impact of disability can benefit physicians who work in specialties such as internal medicine, family medicine, surgery, and psychiatry, ${ }^{9}$ where they will likely encounter children or adults with disabilities or their family members.

The number of people with disabilities across the age span is growing, validating the need for physicians to be prepared to meet their health care needs. During 2014-2016, the prevalence of children aged 3 to 17 years with a diagnosed developmental disability such as autism spectrum disorder, intellectual disability, communication disorders, and learning disabilities, increased from $5.76 \%$ to $6.99 \%{ }^{10}$

Currently, most training for physicians in the area of developmental disability and special education occurs during pediatric residency or residency periods for specialty areas (eg, developmental pediatrics, family medicine), with training often dependent on mentor contributions. ${ }^{11-14}$ Research on training is primarily focused on medical students' attitudes toward people with disabilities rather than on their knowledge of special education law and practices. ${ }^{15}$ A study by Shah et al ${ }^{16}$ demonstrated a disconnect between pediatricians' attitudes about special education and reported practices. The authors speculated that a lack of specific training regarding the special education process may explain the discrepancy. Moreover, primary care physicians recommended modifying their medical school experience by including experiential learning ${ }^{3}$ and expanding disability-specific education to better equip them to care for patients with disabilities. ${ }^{17}$

We are currently developing curricula to improve medical students' knowledge, attitudes, and skills in the area of treating children with disabilities and collaborating with these patients' families. The objectives of the current study were to develop an instrument to measure what second-year medical students knew about children with disabilities and special education law and available services, to determine the most common sources of this information, and to use the pilot data to establish a baseline on which to design curricula. 


\section{Methods}

\section{Study Design}

This pilot study used a nonexperimental survey design with a convenience sample of second-year medical students from a school of osteopathic medicine in the Northeastern United States in April 2015. The study received approval by the institutional review board. Students nearing the end of their second year were asked to complete an online survey as a part of their coursework in either the traditional curriculum or problem-based learning curriculum. Participation was not mandatory. A Qualtrics survey link was provided through Blackboard as part of a pediatrics course taught by one of the authors (J.M.K.). One follow-up email was sent via a course-embedded announcement through Blackboard 5 days after the survey was deployed. Participation was anonymous. Incentives for participation were not provided, and students were expected to complete the survey within 1 week.

\section{Instrument Development}

A review of the medical literature did not yield any validated instruments to measure knowledge related to special education law and practices designed specifically for medical students. Two previously published instruments for practicing physicians ${ }^{3,16}$ were used to inform survey development and provide validity. Items related to sources of information about children with disabilities were adapted from the Beginning Teacher Candidate Autism Spectrum Disorder Knowledge Survey. ${ }^{18}$

Twenty-one survey items were organized into a demographics section and 3 domains. Domain 1 measured perceived level of knowledge about children with disabilities with 1 item: "How much do you know about children with disabilities?" Respondents were asked to rate their knowledge on a Likert scale with the following choices: nothing, a little, quite a bit, and a great deal. Domain 2 addressed sources of information about children with disabilities with 1 question: "What are your sources of knowledge about children with disabilities?" Given 5 options, respon- dents checked all that applied: mass media, disability awareness training, personal communication, personal experience, and coursework. Respondents indicating mass media specified media type(s), and respondents indicating personal experience were asked to clarify the relationship. Domain 3 measured knowledge about children with disabilities and special education through 10 items. Five questions regarding special education knowledge were used with permission from the survey by Shah et al. ${ }^{16}$ We developed 5 additional questions to address EI, 504 plans, autism spectrum disorder prevalence and treatment, and whether parents would ask physicians about special education services for their children (Table 3).

\section{Statistical Analysis}

Descriptive statistics were used for demographics and question responses. Correlational analysis was completed to assess relationships between questions. $t$ tests were also used to assess mean differences in perceived knowledge questions. $P=.05$ was used to establish statistical significance. The Cronbach $\alpha$ was used to assess internal consistency. The data were analyzed by comparing the student responses in Domains 1 and 2 with the number of correct responses in Domain 3. Independent samples $t$ tests were used to compare the mean correct responses of each source group to mean correct responses of students who did not select that as a source of information.

\section{Results}

Of 150 students invited, 98 participated, providing a $65 \%$ response rate. The characteristics of this sample (Table 1) were representative of the second-year class of medical students as a whole.

\section{Perceived Knowledge About Children With Disabilities}

Most students (76 [77.6\%]) reported that they knew a little about children with disabilities, 11 (11.2\%) reported knowing quite a bit, 7 (7.1\%) reported that 


\section{Table 1. \\ Demographic Information of Respondents to Survey Assessing Medical Students' Perceived Knowledge of Children With Disabilities ( $N=98)$}

\begin{tabular}{|c|c|}
\hline haracteristics & No (\%) \\
\hline \multicolumn{2}{|l|}{ Gender } \\
\hline Female & $48(49.0)$ \\
\hline Male & $50(51.0)$ \\
\hline \multicolumn{2}{|l|}{ Racial/Ethnic Group } \\
\hline African American & $5(5.1)$ \\
\hline Asian or Pacific Islander & $41(41.8)$ \\
\hline Hispanic/Latino & $4(4.1$ \\
\hline Mixed race & $1(1.0$ \\
\hline White & $35(35.7)$ \\
\hline Prefer not to respond & $12(12.2)$ \\
\hline \multicolumn{2}{|l|}{ Major ${ }^{a}$} \\
\hline Biology & $58(59.2)$ \\
\hline Chemistry & $3(3.1)$ \\
\hline Health and Exercise Science & $13(13.3)$ \\
\hline Liberal arts & $15(15.3)$ \\
\hline Neuroscience & $8(8.2)$ \\
\hline Public health & $1(1.0)$ \\
\hline
\end{tabular}

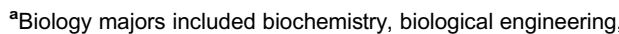
biological science, cell biology, cellular and molecular biology, and genetics. Liberal arts majors included anthropology, classics, ecology, economics, engineering, English, environmental studies,

humanistic studies, sociology, and Spanish.

they knew nothing, and $4(4.1 \%)$ reported that they knew a great deal (Table 2). A Pearson $r$ used to compare the relationships between these responses with the number of correct responses showed that perceived knowledge was positively correlated to actual knowledge $(r=0.197, P=.05)$.

\section{Knowledge of Special Education}

The students knew little about special education policies and practices (mean [SD] correct responses out of a possible 10, 2.38 [1.67]). The mean (SD) out of a possible 10 for each were also calculated for incorrect responses and "uncertain" (Table 3).

\section{Table 2. \\ Domain 1 of Survey Assessing Medical Students' Perceived Knowledge of Children With Disabilities: How much do you know about children with disabilities? $(\mathbf{N}=98)$}

\begin{tabular}{lr} 
Knowledge of Children With Disabilities & No. (\%) \\
\hline I know nothing about children with disabilities. & $7(7.1)$ \\
\hline I know a little about children with disabilities. & $76(77.6)$ \\
\hline I know quite a bit about children with disabilities. & $11(11.2)$ \\
\hline $\begin{array}{l}\text { I know a great deal about children with } \\
\text { disabilities. }\end{array}$ & $4(4.1)$ \\
\hline Total & $98(100)$ \\
\hline
\end{tabular}

\section{Sources of Knowledge}

Mass media and personal communication were most often identified as sources of knowledge (Table 4). Students who identified personal relationships and those who identified coursework as a source of information had the most correct responses in Domain 3. Students who identified mass media and disability awareness training as sources of information had the fewest correct responses. The only significant difference was found between the mean correct responses of students who identified coursework as a source of information and those who did not $(t=2.62, P \leq .01)$.

\section{Psychometric Analysis}

The Chronbach $\alpha$ for the 10 knowledge questions was 0.781 for standardized items. This value fell within the acceptable range of 0.70 to 0.95 , indicating satisfactory reliability. The item analysis found that the removal of no single item would significantly affect the Chronbach $\alpha$, and the small range of values (0.749-0.777) demonstrated consistency across items.

\section{Discussion}

In this study, 98 respondents from a second-year pediatric course shared their baseline knowledge about children with disabilities, special education law, available services, and the sources of this information. Topics 
Table 3.

Domain 3 of Survey Assessing Medical Students' Perceived Knowledge of Children With Disabilities: Overall Level of Knowledge ${ }^{a}(\mathbf{N}=98)$

\begin{tabular}{|c|c|c|c|c|}
\hline Item & $\begin{array}{c}\text { Correct } \\
\text { Response }\end{array}$ & $\begin{array}{l}\text { Responded } \\
\text { Correctly }\end{array}$ & $\begin{array}{l}\text { Responded } \\
\text { Incorrectly }\end{array}$ & Uncertain \\
\hline $\begin{array}{l}\text { Each child with a disability must have an } \\
\text { individualized education program (IEP). }\end{array}$ & False & $16(16.3)$ & $51(52.0)$ & 31 (31.6) \\
\hline $\begin{array}{l}\text { According to the Individuals with Disabilities } \\
\text { Education Act (IDEA) of } 2004 \text {, each child with an IEP } \\
\text { should receive special education services in a } \\
\text { separate classroom designed to meet the needs of } \\
\text { his/her disability. }\end{array}$ & False & $27(27.6)$ & $33(33.7)$ & $38(38.8)$ \\
\hline $\begin{array}{l}\text { Children with a genetic complication (eg, Down } \\
\text { syndrome, fragile X) automatically qualify for special } \\
\text { education services. }\end{array}$ & False & $14(14.3)$ & $55(56.1)$ & $29(29.6)$ \\
\hline $\begin{array}{l}\text { A physician's prescription for an IEP mandates that } \\
\text { the school develop an IEP for a child. }\end{array}$ & False & $15(15.3)$ & 39 (39.8) & $44(44.9)$ \\
\hline $\begin{array}{l}\text { In order for a child to receive early intervention } \\
\text { services, he or she must have an identified disability. }\end{array}$ & False & $13(13.3)$ & $55(56.1)$ & $30(30.6)$ \\
\hline $\begin{array}{l}\text { An IEP and a } 504 \text { plan afford a child with disabilities } \\
\text { the same level of legal protections. }\end{array}$ & False & $16(16.3)$ & $30(30.6)$ & $52(53.1)$ \\
\hline $\begin{array}{l}\text { Discreet trial training is the only evidence-based } \\
\text { practice that is effective for teaching children with } \\
\text { autism. }\end{array}$ & False & $17(17.3)$ & $13(13.3)$ & $68(69.4)$ \\
\hline
\end{tabular}

a Data are given as No. (\%) unless otherwise indicated.

included IDEA, the individualized education program, 504 plans, EI services, and the role of physicians in assisting families with these issues. These topics had not been previously addressed in the first- and secondyear medical school curriculum for these participants and are not topics that have been widely included in medical school curricula. ${ }^{19}$

The perception of knowledge and actual knowledge among the medical students surveyed was congruous. Yet although students were accurate in their self- assessment, their actual fund of knowledge regarding children with disabilities was found to be limited. The deficit in knowledge regarding eligibility for special education services and specific interventions was evidenced in the few correct and many uncertain responses to most questions. However, most students understood the need for inclusion of these topics in the medical school curriculum, ${ }^{14}$ as $69.4 \%$ of them correctly responded true to the statement "Parents of children with disabilities will consult their doctors on matters of therapeutic 
Table 4.

Domain 2 of Survey Assessing Medical Students' Perceived Knowledge of Children With Disabilities: Mean Responses: Examined in the Context of Sources of Knowledge

\begin{tabular}{|c|c|c|c|}
\hline & \multicolumn{2}{|c|}{ Source Used } & \\
\hline & Yes & No & \\
\hline Sources of Knowledge ${ }^{a}$ & Mean (SD) & Mean (SD) & $t(97)$ \\
\hline Correct Responses $^{b}$ & & & \\
\hline Mass media & $2.32(1.69)$ & $2.49(1.63)$ & 0.483 \\
\hline Disability awareness training & $2.36(1.78)$ & $2.39(1.58)$ & 0.088 \\
\hline Personal communication & $2.46(1.75)$ & $2.17(1.44)$ & 0.786 \\
\hline Personal experiences & $2.68(1.68)$ & $2.13(1.63)$ & 1.642 \\
\hline Coursework & $2.94(1.88)$ & $2.05(1.44)$ & $2.625^{\mathrm{C}}$ \\
\hline Incorrect Responses & & & \\
\hline Mass media & $4.05(2.45)$ & $3.23(1.96)$ & 1.70 \\
\hline Disability awareness training & $3.57(2.55)$ & $3.91(2.1)$ & 0.722 \\
\hline Personal communication & $3.48(2.32)$ & $4.41(2.18)$ & 1.856 \\
\hline Personal experiences & $3.34(2.22)$ & $4.09(2.34)$ & 1.617 \\
\hline Coursework & $3.55(2.13)$ & $3.87(2.41)$ & 0.65 \\
\hline Did Not Know & & & \\
\hline Mass media & $3.63(3.03)$ & $4.29(2.49)$ & 1.083 \\
\hline Disability awareness training & $4.07(3.14)$ & $3.7(2.61)$ & 0.627 \\
\hline Personal communication & $4.06(2.92)$ & $3.41(2.66)$ & 1.021 \\
\hline Personal experiences & $3.78(2.91)$ & $3.97(2.81)$ & 0.343 \\
\hline Coursework & $3.5(2.27)$ & $4.08(2.92)$ & 0.971 \\
\hline
\end{tabular}

a Participants were allowed to select multiple sources.

b Out of a possible 10.

c $P \leq .01$.

and educational options for their children." This finding demonstrates the need for intervention.

Personal relationships and coursework seemed to provide more accurate information about children with disabilities and special education. Mass media and disability awareness training were limited as sources of information. Coursework yielded the most accurate knowledge regarding children with disabilities. The positive association between coursework and accurate information indicates the importance of implementing effective curricula.
This study demonstrated that second-year medical students enrolled in 1 school of osteopathic medicine lacked knowledge regarding disabilities and special education. The students were aware of the gaps in their knowledge but also appreciated that as physicians, they would be consulted in these matters by patients and families. These data illustrate the need for training medical students in this area. However, residency education in developmental/behavioral pediatrics, where this topic has traditionally been introduced, has been found to be deficient for many practicing physicians. ${ }^{20}$ 
The absence of comprehensive training on the topics of disabilities, including screening, interventions, communication, and providing appropriate medical care has led to health disparities in this population. ${ }^{21}$ These disparities further exemplify the need for the earlier introduction of these topics in medical education to ensure that they are addressed and reach the broadest group of future physicians. Personal relationships and coursework are effective in conveying information about children with disabilities and special education. Such findings provide a framework on which to deliver this material to medical students. Curricula that emphasize this topic along with longitudinal experiential training are effective instructional methods. ${ }^{19}$

The context of osteopathic medicine as a distinct form of medical practice is vital when discussing study findings and significance. Osteopathic physicians value the person as a unit of body, mind, and spirit and are trained to integrate the comprehensive treatment principle into the provision of collaborative and culturally competent care. ${ }^{22}$ Touch and empathetic communication create a bond that enriches the patient-physician relationship. ${ }^{23}$ These principles extend to the care of children with disabilities and their families. Osteopathic medical students will enhance their interpersonal and communications skills, their diagnostic acumen, their ability to form a clinical question, and their ability to collaborate as a member of an interprofessional team. Expanding these skills will further develop competence in entrustable professional activities as they learn about children with disabilities and special education law. ${ }^{24}$

\section{Limitations}

The sample size and focus on 1 school of osteopathic medicine are limitations to the study. The findings, although not generalizable, are applicable to the institution where the study took place and can serve as a model for other medical education programs. It should be noted that not all students who enrolled in the course submitted a survey response, which may reflect a lack of investment in the content. Self-reported data obtained through a survey design can contain potential sources of bias, such as selective memory and diverse interpretations of questions that can affect responses. These limitations were considered prior to drawing conclusions.

\section{Directions for Future Research}

This pilot study serves as a baseline on which to build novel educational experiences in our program. In addition to the acquisition of new information, we believe that active learning is required for the application of the knowledge and use of critical thinking. ${ }^{25}$ Therefore, proposed curricular changes will balance coursework with personal experiences through experiential learning.

Future directions include the revision of the survey tool. When considering the pattern of responses to the true/false questions, most of the correct responses were false. We acknowledge the need to avoid a disproportionate number of true or false statements.

\section{Conclusion}

The results of this survey, along with prior research, ${ }^{20-22}$ provided evidence needed for revision of the curriculum at 1 particular school of osteopathic medicine to include the topics of disability and special education. It is especially significant that second-year medical students recognize that physicians are an important resource for families when discussing disabilities and special education. Further research is needed with regard to effective instruction and to determine whether the early introduction of this education will better prepare physicians to be competent in treating children with disabilities, working with their families, and collaborating with teachers and school personnel.

\section{References}

1. Adams RC, Tapia C. Council on Children with Disabilities. Early intervention, IDEA part $\mathrm{C}$ services, and the medical home: collaboration for best practice and best outcomes. Pediatrics. 2013;132 (4):e1073-e1088. doi:10.1542/peds.2013-2305 
2. Lipkin PH, Okamoto J. Council for Children with Disabilities. Council on School Health. The Individuals with Disabilities Education Act (IDEA) for children with special educational needs. Pediatrics. 2015;136(6):2015-3409. doi:10.1542/peds.2015-3409

3. Hastings EA, Lumeng JC, Clark, SJ. Primary care physicians knowledge of and confidence in their referrals for special education services in 3- to 5-year-old children. Clin Pediatr. 2014;53(2):166-172. doi:10.1177/0009922813503036

4. Individuals with Disabilities Education Improvement Act of 2004. Pub. L. No. 108-446, § 101, 118 Stat. 2647 (codified at 20 U.S.C $\S$ 1400 (c)(2) (2010)).

5. Bailey DB, Hebbeler K, Scarborough A, Spiker D, Mallik S. First experiences with early intervention: a national perspective. Pediatrics. 2004;113(4):887-896.

6. Shonkoff JP, Phillips DA, eds. From Neurons to Neighborhoods: The Science of Early Childhood Development. Washington, DC: National Academies Press; 2000:337-380.

7. Rose L, Herzig LD, Hussey-Gardner B. Early intervention and the role of pediatricians. Pediatr Rev. 2014;35(1);el. doi:10.1542/pir.35-1-e1

8. Betz CL. Use of 504 plans for children and youth with disabilities: nursing application. Pediatr Nurs. 2001;27(4):347-52.

9. Wilkinson J, Dreyfus D, Cerreto M, Bokhour B. "Sometimes I fee overwhelmed": educational needs of family physicians caring for people with intellectual disability. Intellect Dev Disabil. 2012;50 (3):243-250. doi:10.1352/1934-9556-50.3.243

10. Zablotsky B, Black LI, Blumberg SJ. Estimated Prevalence of Children With Diagnosed Developmental Disabilities in the United States, 20142016. Washington, DC: National Center for Health Statistics; 2017. https://www.cdc.gov/nchs/data/databriefs/db291.pdf. Accessed August 19, 2019.

11. Sheppard ME, Vitalone-Raccaro N. How physicians support children with disabilities and their families: roles, responsibilities and collaborative partnerships. Disabil Health J. 2016;9:692-704 doi:0.1016/j.dhjo.2016.05.007

12. Bogetz JF, Gabhart JM, Rassbach CE, et al. Outcomes of a randomized controlled educational intervention to train pediatric residents on caring for children with special health care needs. Clinical Peds. 2015;54(7):659-666. doi:10.1177/0009922814564050

13. Boreman CD, Thomasgard MC, Fernandez SA, Coury DL. Resident training in developmental/behavioral pediatrics: where do we stand? Clinical Peds. 2007;46(2):135-145. doi:10.1177/0009922806290456
14. Nazarian BL, Glader L, Choueiri R, Shipman DL, Sadof M. Identifying what pediatric residents are taught about children and youth with special health care needs and the medical home. Pediatrics. 2010;126 (suppl 3):S183-S189. doi:10.1542/peds.2010-1466O

15. Ryan TA, Scior K. Medical students' attitudes towards people with intellectual disabilities: a literature review. Res Dev Disabil. 2014;35 (10):2316-2328. doi:10.1016/j.ridd.2014.05.019

16. Shah RP, Kunnavakkam R, Msall ME. Pediatrician's knowledge, attitudes, and practice patterns regarding special education and individualized education programs. Acad Pediatr. 2013;13(5):430-435. doi:10.1016/j.acap.2013.03.003

17. Minnes $P$, Steiner $K$. Parent views on enhancing the quality of health care for their children with fragile $X$ syndrome, autism or Down syndrome. J Autism Dev Disord. 2010;40(3):317-324. doi:10.1007/ s10803-009-0874-5

18. Blackwell W, Sheppard ME, Lehr D, Huang S. Examining pre-service teacher candidates' sources and levels of knowledge about autism spectrum disorders. J Human Services Train Res Practice. 2017;2 (2):1-25.

19. Boreman CD, Thomasgard MC, Fernandez SA, Coury DL. Resident training in developmental/behavioral pediatrics: where do we stand? Clin Pediatr. 2007;46(2):135-145. doi:10.1177/ 0009922806290456

20. Eddey GE, Robey KL. Considering the culture of disability in cultural competence education. Acad Med. 2005;80(7):706-712.

21. Woodward LJ. An innovative clerkship module focused on patients with disabilities. Acad Med. 2012;87(4):537-542. doi:10.1097/ ACM.0b013e318248ed0a

22. Tenets of osteopathic medicine. American Osteopathic Association website. http://www.osteopathic.org/inside-aoa/about/leadership/ Pages/tenets-of-osteopathic-medicine.aspx. Accessed June 22, 2018.

23. Elkiss M, Jerome JA. Touch—more than a basic science. J Am Osteopathic Assoc. 2012;112(8):514-517.

24. Osteopathic Considerations for Core Entrustable Professional Activities (EPAs) for Entering Residency. Chevy Chase, MD: American Association of Colleges of Osteopathic Medicine; 2016.

25. Khanova J, Roth MT, Rodgers JE, McLaughlin JE. Student experiences across multiple flipped courses in a single curriculum. Med Educ. 2015;49(10):1038-1048. doi:10.1111/medu.12807

(c) 2019 American Osteopathic Association 